\title{
PROJETO, DESENVOLVIMENTO E EVOLUÇÃO DE UMA REDE SOCIAL DE SUPORTE À APRENDIZAGEM CLÍNICA
}

\author{
Douglas da Cruz Cerqueira $^{1}$; Roberto Almeida Bittencourt ${ }^{2}$ \\ 1. Bolsista PIBIC/FAPESB, Graduando em Engenharia da Computação, Universidade \\ Estadual de Feira de Santana, email: douglasdacruzz@gmail.com \\ 2. Orientador, Departamento de Ciências Exatas (DEXA), Universidade Estadual de Feira de \\ Santana, email: roberto@uefs.br \\ PALAVRAS-CHAVE: aprendizagem clínica, redes sociais, fórum de discussão
}

\section{INTRODUÇÃO}

Durante seus cursos de graduação na área de saúde, a fim de aplicar e consolidar seus conhecimentos, os alunos recebem aulas e capacitações práticas sob a supervisão de professores. O período em que os alunos passam em disciplinas que possuem atividades práticas é chamado de prática clínica. Durante esse período, o aluno desenvolve sua capacidade de análise e reflexão, bem como uma formação específica em determinada área.

Apesar do crescimento do uso de tecnologias computacionais na área de educação e saúde, é comum que este uso se restrinja à disponibilização de informação e conteúdo. Em ambientes não educacionais, as tecnologias se limitam a fomentar a relação entre médicos e médico-paciente. De maneira geral, os ambientes computacionais virtuais não buscam a construção de conteúdo colaborativo, entre médicos ou entre alunos e professores.

A deficiência na comunicação entre os participantes é principal fator que limita o processo do ensino e da aprendizagem clínica em cursos da área de saúde (CHAVES; GROSSEMAN, 2007). O conhecimento prático adquirido no contato com os pacientes muitas vezes fica restrito aos estudantes e/ou profissionais que tiveram o contato com estes pacientes, dificultando o compartilhamento do conhecimento.

Para facilitar a comunicação diversos modelos colaborativos foram propostos, e vários deles compartilham de certa semelhança, para eles um groupware deve fornecer comunicação, coordenação e cooperação. O modelo que abrange esses três artefatos denomina-se Modelo 3C de Colaboração (PIMENTEL et al., 2006).

Para ajudar nas dificuldades de discussão de casos clínicos, propomos uma ferramenta colaborativa para a discussão de casos clínicos em cursos de saúde. Sob supervisão e auxílio de professores, a ferramenta permite que alunos discutam casos reais e compartilhem o conhecimento adquirido no diagnóstico de enfermidades e em seu tratamento.

Neste trabalho, nós evoluímos e avaliamos a ferramenta previamente desenvolvida no ano anterior de iniciação científica. A evolução da ferramenta foi feita após um processo de validação junto a professores e alunos. Através da observação de uso e relatos destes alunos e professores, notamos que algumas alterações seriam necessárias na ferramenta para que pudéssemos utilizá-la plenamente e avaliá-la cientificamente.

O processo de avaliação passou por três etapas, uma primeira se deu por uma avaliação cooperativa para validação da ferramenta, uma avaliação dos estudantes e professores antes do uso da ferramenta, e uma avaliação posterior ao uso da ferramenta. As avaliações foram encorajadoras mostrando um aumento na aprendizagem e deixando claro o que pode ser alcançado com trabalho em grupo.

\section{METODOLOGIA}


O desenvolvimento deste projeto contou com duas etapas, as quais consistiam em evoluir e avaliar o sistema anteriormente desenvolvido e aprovado por professores do curso de odontologia.

A partir da versão anterior, apresentada e aprovada por alguns professores do curso de Odontologia, aplicamos o método de avaliação cooperativa para validar o sistema com os alunos que o utilizariam durante o semestre. Com a realização da avaliação cooperativa, algumas falhas e melhorias foram levantadas e foi feita uma revisão das funcionalidades do sistema. Tal revisão de funcionalidades envolveu a remoção e alteração de funcionalidades já existentes, além de novas funcionalidades, que foram implementadas a pedido de alunos e professores. Após a revisão, foram realizados testes para garantir a consistência das novas funcionalidades e daquelas alteradas.

Em seguida, passamos para a fase de avaliação do sistema. Para tal avaliação, foi utilizada uma metodologia quantitativa e qualitativa através das coletas de dados realizadas antes e depois do uso do sistema pelos alunos e professores voluntários. Para a coleta de dados, foram utilizados questionários, entrevistas e análise de logs do sistema, resultantes do uso dos voluntários. O sistema foi validado com a utilização de 26 pessoas, sendo dois professores e 24 alunos. Para avaliação do nível do sistema e seu impacto na cooperação dos alunos, o modelo de maturidade CollabMM foi utilizado (MAGDALENO; ARAUJO; BORGES, 2007). O modelo CollabMM busca apontar em que nível de maturidade se encontra o processo de colaboração para que se possa alcançar um nível mais elevado. Como pode ser visto na Figura 1 , este modelo apresenta 4 níveis.

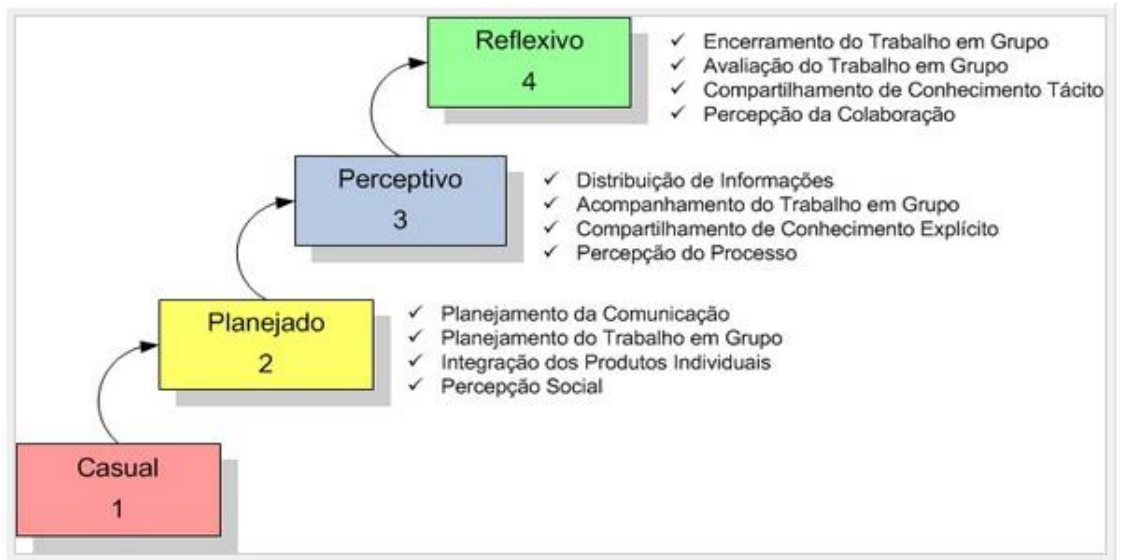

Figura 1. Níveis de maturidade do modelo CollabMM.

\section{RESULTADOS}

\section{Avaliação Cooperativa}

Os resultados de avaliação cooperativa foram encorajadores. Os alunos e professores apontaram não só falhas de conceito, mas também melhorias para adaptar o sistema ao ambiente da clínica. Também apresentaram os prós e contras do sistema. Os resultados são apresentados abaixo.

Dados os pontos positivos do projeto e as possíveis modificações desejadas, vale considerar as percepções sobre os usuários. Os alunos se mostraram bastante motivados e consideraram muito a possibilidade de manter o sistema em uso durante suas atividades clínicas. 
Consideraram o sistema de fácil navegação, e levantaram a possibilidade de integração com outros sistemas da clínica.

Quanto ao uso da ferramenta pelos alunos, o que mais demandou tempo deles foi elaborar a forma como o caso clínico seria postado. Acreditamos que por causa do contato frequente com o prontuário médico e com a necessidade de organização e padronização dos prontuários, eles estivessem tentando trazer isso para a ferramenta.

A maior dificuldade mostrada pelos alunos durante a avaliação era como dissertar os campos do caso clínico. Acreditamos que para o primeiro contato com a ferramenta, os alunos tenham tentado manter um certo nível de formalismo, utilizando termos e um fluxo de discussões técnicas e bastante próximas de um prontuário. Era esperado que ambiente fosse utilizado de forma mais descontraída.

\section{Avaliação Quantitativa}

A etapa de avaliação quantitativa ocorreu depois da aplicação da ferramenta. Com foco na ferramenta, avaliamos a usabilidade e o potencial de aprendizagem dos usuários através de um questionário. As questões variaram entre respostas de sim ou não e repostas numa escala de Likert de 1 a 5 .

Nesta modalidade, os questionamentos buscavam compreender a relação dos usuários com o fluxo do sistema e como esse uso auxiliaria o processo de aprendizagem. Atribuímos a baixa avalição no quesito facilidade do ambiente devido aos problemas enfrentados pelos usuários para acessar o sistema. A socialização entre alunos e entre alunos e professores foi um dos valores mais pontuados pelos alunos.

Do ponto de vista colaborativo, o sistema tinha como objetivo fomentar a comunicação, a cooperação e a coordenação. Também com escala variando de 1 a 5 (de nada a muito), os resultados foram animadores. Ficou claro que os estudantes passaram a ver os trabalhos de seus colegas sob outra perspectiva, com mais interesse e querendo ajudar em suas resoluções. Porém, na visão dos alunos, a comunicação entre alunos e professores não teve uma mudança considerável.

\section{Avaliação Qualitativa}

O processo de avaliação qualitativa ocorreu anterior e posteriormente à utilização da ferramenta.

A comunicação entre alunos e professores ocorria para esclarecimentos diversos, principalmente durante a condução das atividades que eram realizadas e utilizando da troca de e-mails, ou seja, de forma tradicional. Entre os participantes, essa comunicação acontece de maneira mais informal, principalmente utilizando de redes sociais como Facebook e Whatsapp.

A utilização do ambiente revelou a necessidade da criação de ambientes formais para discussão desses casos e assuntos diversos. Após a utilização do ambiente, a contribuição dos participantes para a construção de diagnósticos e tratamentos aumentou. Entre os estudantes, o ambiente possibilitou que as duplas discutissem sobre temas que não eram de seu domínio, com os quais não teriam contato enquanto cuidam de seus próprios casos clínicos.

A cooperação entre os estudantes ocorria, em sua maioria, entre as duplas responsáveis por seus casos clínicos. A utilização do ambiente claramente, através da construção dos casos 
clínicos, estendeu essa cooperação para outras pessoas. O processo de coordenação ocorria principalmente na interação entre os professores. Esse processo de coordenação continuou a ocorrer principalmente em âmbito presencial, durante o funcionamento da clínica, não sendo modificado pelo ambiente.

\section{Avaliação Quali-Quantitativa de Logs}

Esta avaliação permitiu verificar a postura dos alunos diante do uso da ferramenta. O uso da ferramenta ocorreu principalmente para confirmação de dúvidas que os alunos possuíam sobre os casos trabalhados pelos seus colegas. Conforme pôde ser extraído dos logs analisados, o fluxo de trabalho em um caso seguia o mesmo processo utilizado no ambiente real. Os alunos alimentavam a postagem com informações sobre os pacientes e, a partir destas informações, havia discussão sobre diagnósticos e tratamentos da doença.

Com a leitura dos dados dos logs retirados após o uso da ferramenta, vimos que 17 discussões de casos clínicos foram abertas, enquanto um total de 77 comentários foram feitos entre os participantes. Tais comentários se concentraram principalmente na seção de discussão do diagnóstico e, em segundo lugar, na discussão de tratamento.

\section{CONSIDERAÇÕES FINAIS}

Com a avaliação do ambiente, fomos capazes de comprovar a melhoria na aprendizagem, proporcionando meios por onde fomentar a interação entre os estudantes e professores. Uma análise do ponto de vista do modelo de maturidade de colaboração (CollabMM) tornou mais visível a diferença entre o antes e depois do ambiente.

Com o uso do ambiente, ficou claro para todos os envolvidos o potencial que havia e que podia ser alcançado através do trabalho em grupo. A percepção que o ambiente deu sobre os trabalhos dos colegas despertou a vontade de descobrir o que se passava na clínica, que ia além de cada trabalho pessoalmente desenvolvido, motivando a cooperação de todos.

Os novos requisitos do ambiente foram obtidos a partir de uma avaliação cooperativa para validação do ambiente. O ambiente também foi avaliado do ponto de vista qualitativo e quantitativo. Assim, sendo possível quantificar o nível de influência da ferramenta no processo de aprendizagem no curso de odontologia. Com as avaliações feitas, é possível afirmar a capacidade que a ferramenta possui para auxiliar os pilares de um trabalho colaborativo em seus aspectos de comunicação, cooperação e coordenação.

\section{REFERÊNCIAS}

CHAVES, I.; GROSSEMAN, S. Medical internship and its perspectives: a case study with educators and students. Revista Brasileira de Educação Médica, p. 212-222, 2007.

MAGDALENO, A.; ARAUJO, R.; BORGES, M. Designing Collaborative Processes. BPMDS. International Workshop on Business Process Modeling, Development and Supp, p. 283-290, 2007.

PIMENTEL, M.; GEROSA, M. A., FILIPPO, D.; RAPOSO A.; FUKS, H.; LUCENA. C. J. P. Modelo 3c de colaboração para o desenvolvimento de sistemas colaborativos. Anais do III Simpósio Brasileiro de Sistemas Colaborativos, p. 58-67, 2006. 